\title{
PRODUCTION OF MOULDING CORES AND WATERGLASS MIXTURES USING "DRY ICE" FOR STEEL AND IRON CASTING
}

\author{
I. O. Leushin ${ }^{1}$, L. I. Leushina1, I. P. Balabanov ${ }^{2,3}$, I. A. Savin ${ }^{3}$ \\ ${ }^{1}$ Nizhniy Novgorod State Technical University (Nizhniy Novgorod, Russia), \\ ${ }^{2}$ Kazan Federal University (Kazan, Russia). \\ ${ }^{3}$ Kazan National Research Technical University named after A.N. Tupolev - KAI (Kazan, Russia)
}

E-mail: igoleu@yandex.ru; kafmto@mail.ru; balabanovip@mail.ru; savin.ia@kaichelny.ru

\section{A UTHOR'S INFO \\ I. O. Leushin, Dr. Eng., Prof., Dept. "Metallurgical Technologies and Equipment" L. I. Leushina \\ Cand. Eng., \\ Associate Prof., Dept. "Metallurgical Technologies and Equipment" I. P. Balabanov, Cand. Eng., Associate Prof., Dept. "Automation and Management" \\ I. A. Savin, \\ Cand. Eng., Associate Prof., Head of Dept. "Design and Technology for Machine-building industries"}

Key words:

moulding core, mould, waterglass, mixture, casting, iron casting, steel casting, dry ice.

\author{
A B S T R ACT
}

Increased interest of industrial enterprises to manufacture of moulding cores and moulds of mixtures based on waterglass binder is connected with acceptability and high ecological safety of this material. It stipulated more active work for searching technical solutions that can decrease or exclude deficiencies of such technologies as carbon dioxide blowing and thermal effect that are mostly popular at Russian enterprises. Among these deficiencies, the following can be mentioned for example: low setting rates during blowing of waterglass mixtures in the normal temperature conditions as well as the effect of noncontrolled moisture migration in a moulding core of mould body during heating. Their appearances lead to deterioration of operation parameters of core or mould, such as lowering of surface strength, increase of friability, elevation of strength of internal parts of core or mould, what enlarges the risk of their poor knock-out ability from steel and iron castings. Analytical survey of accessible information data was conducted by the authors of this paper; they revealed two directions in searching the solution of the a.m. problem that were supported by overwhelming majority of the researchers. These directions include directed vacuum treatment of technological accessories for increase of control abilities of moisture migration in a body of core or mould, as well as technological additives of different origination in the mixture composition for provision of timely softening of core or mould during knock-out operation out of casting. However, their use does not guarantee always the stable positive effect, thereby this task is still not solved. The authors of this paper concentrated their attention on the problem of development and testing the innovative technology of production of moulding cores and moulds of waterglass mixtures in the conditions of operating enterprise. This technology allows to improve their operating properties and parameters, to lower the mentioned deficiencies and as a result to stabilize the quality of cast metallic billets of steel and iron at the high level. Solving of this task is based on well-known combination of chemical and physical mechanisms of setting of waterglass mixtures together with directed vacuum treatment of technological accessories during acquiring of the required geometrical shape by a moulding core or mould. In this case the following consequent operations tale place: filling of moulding core or moulding box accessories by mixture; its compacting and strengthening via passing of heated setting gas through the mixture from the one side of core or mould with simultaneous its consumption from the other side due to adjustable exhausting. The authors substantiated scientifically and proved experimentally expedience of introduction of small amount of solid carbon dioxide ("dry ice") in the form of particles with preset size and compensation of inevitably occurring undesirable endothermic effect of setting gas heating (air in this case) up to higher temperature in comparison with well-known prototype. Testing of the suggested solution in the conditions of operating production facilities confirmed its practical efficiency.

\section{Introduction}

Increased interest of industrial enterprises to manufacture of moulding cores and moulds of mixtures based on waterglass binder (WB) is connected with high ecological safety of this material and lack of alternative in the same range of price and technical possibilities [1-6].

National producers use mainly for acquiring of the required geometrical shape to casting moulds or moulding cores of waterglass mixtures such effects on the material located in technological accessories as blowing by carbon dioxide $\left(\mathrm{CO}_{2}\right.$ process $)$ or heating.

However, many researchers who have examined this problem confirmed the facts of presence of substantial deficiencies for these setting mechanisms [7-10]. So, the process of silica gel forming as a result of a known chemical reaction of waterglass blowing by carbon dioxide via $\mathrm{CO}_{2}$ process is characterized by low conduction rate in the normal temperature conditions. Thermal effect on WB final- izes in water steam extraction from it. This steam inevitably enters the internal part of core or mould when no adjusting measures take place, what leads to pressure increase in the total volume and to material gas penetration decrease due to moisture condensation in the peripheral sections located far from the heat source. Additionally, essential lowering of setting rate in the problem sections is observed owing to mixing of condensate moisture and WB moisture and, as a result, WB fluidization. Fluidized WB with lowered binding properties migrates along core (mould) body predictably free and promotes heterogeneous distribution of mixture strength across its cross section in the direction of heat propagation. As a result, the producers obtain the complete package of problems connected with deterioration of core (mould) operating parameters, such as lowering of surface strength, increase of friability, elevation of strength of internal parts, what enlarges the risk of their poor knock-out ability from steel and iron castings, seeming to be so typical for waterglass mixtures. 
Analytical survey of accessible information data was conducted by the authors of this paper; they revealed two directions in searching the solution of the a.m. problem that were supported by overwhelming majority of the researchers. These directions include:

- directed vacuum treatment of technological accessories for increase of control abilities of moisture migration in a body of core or mould [11];

- technological additives of different origination in the mixture composition for provision of timely softening of core or mould during knock-out operation out of casting [12-14].

At the same time different scientists many times confirmed experimentally the fact that even small exhausting degree in the working space of technological accessories leads to essential retarding of core (mould) setting due to endothermic effect arising during moisture evaporation from WB composition.

As concerns efficiency of use of softening technological additives, the practical experience displayed that the stable positive effect based on these measures could not always been fixed.

Thereby the problem remains opened and is still required to be the subject of increased attention of the researchers.

\section{The aim of research}

The authors of this paper formulated the aim of this research as solving the problem of development and testing the technology for manufacture of moulding cores and waterglass moulds in the conditions of operating production facilities. This technology should improve operating properties and parameters of cores and moulds, decrease their above-mentioned deficiencies and, as a result, stabilize the quality of cast metallic billets at the high level.

\section{Choice of the variant for problem solution}

The basis of suggested solution was decided to make as combination of chemical and physical mechanisms of setting of waterglass mixtures together with directed vacuum treatment of technological accessories during acquiring of the required geometrical shape by a moulding core or mould. In this case the following consequent operations tale place: filling of moulding core or moulding box accessories by mixture; its compacting and strengthening via passing of heated setting gas through the mixture from the one side of core or mould with simultaneous its consumption from the other side due to adjustable exhausting. This approach was tested previously in [15].

To solve the above-mentioned problem, it was suggested to introduce small amount of solid carbon dioxide ("dry ice") in the form of particles with preset size in the mixture composition and to compensate inevitably occurring undesirable endothermic effect via setting gas heating up to higher temperature in comparison with the basic technical solution [16].
The following considerations were prerequisites of such suggestion.

Solid carbon dioxide $\mathrm{CO}_{2}$ ("dry ice") is sublimating at atmospheric pressure and room temperature just after transition into gaseous state, while at higher temperature its sublimation process is substantially intensified.

Introduction of "dry ice" with low initial temperature (lower the temperature of sublimation start at $-80{ }^{\circ} \mathrm{C}$ ) in the mixture composition with consequent mixing until its filling the technological accessories allows to save the mixture vitality due to retarding of the mechanisms of chemical and thermal setting at this stage and to distribute particles of additive through the whole mixture volume, providing thereby its homogeneity. In this case the conscious choice of size of the solid additive particles makes it possible to save empty cells in the body of core (mould) after mixture compacting and sublimation of particles. As a result, the cellular structure is forming in the body of core (mould); it is characterized by high values of gas penetration ability and volumetric strength of cast core (mould) material, and at the same time it creates prerequisites of provision of their knock-out stability owing to increased porosity.

Additional adjusting heating of setting gas that is passing through the mixture after its filling the accessories and finishing of compacting operation, not only compensates lowering if the mixture temperature due to adding of cold solid carbon dioxide in this mixture (what promotes intensification of sublimation of "dry ice" particles), but also switches on the physical and chemical mechanisms of casting core (mould) strengthening at the required moment.

Transition of "dry ice" particles in the gaseous state as a result of its sublimation provides supply of the required reactant for $\mathrm{CO}_{2}$ process in the working space of technological accessories through the whole core (mould) volume, and supply of heated setting gas provides intensification of thermal setting of core (mould). It results in increase of process productivity and efficiency.

\section{Experimental testing of validity of technical solution and discussion of the results}

The complex of pilot and experimental works was conducted in the laboratory of the department "Metallurgical technologies and equipment" in the Nizhniy Novgorod State Technical University named after R. E. Alekseev [16].

Core mixture was prepared on the base of quartzite sand, it contained 5.0 mass \% of sodium waterglass with the module of 2.7 units and density equals to $1.32 \mathrm{~g} / \mathrm{cm}^{3}$. Air was used as setting gas, it was supplied by air blower through a pipeline with electric heating spiral. Vacuum treatment of core box was conducted with $0.05 \mathrm{MPa}$ exhausting.

Pilot cores with mass 0.5 ; 1.2 and $5.0 \mathrm{~kg}$ were chosen. Time of their complete setting was measured via varying of the heating temperature of setting gas. Time control was realized via conductometric method based on residual electric conductivity after complete setting of mix taken off from electrodes located in the center of 

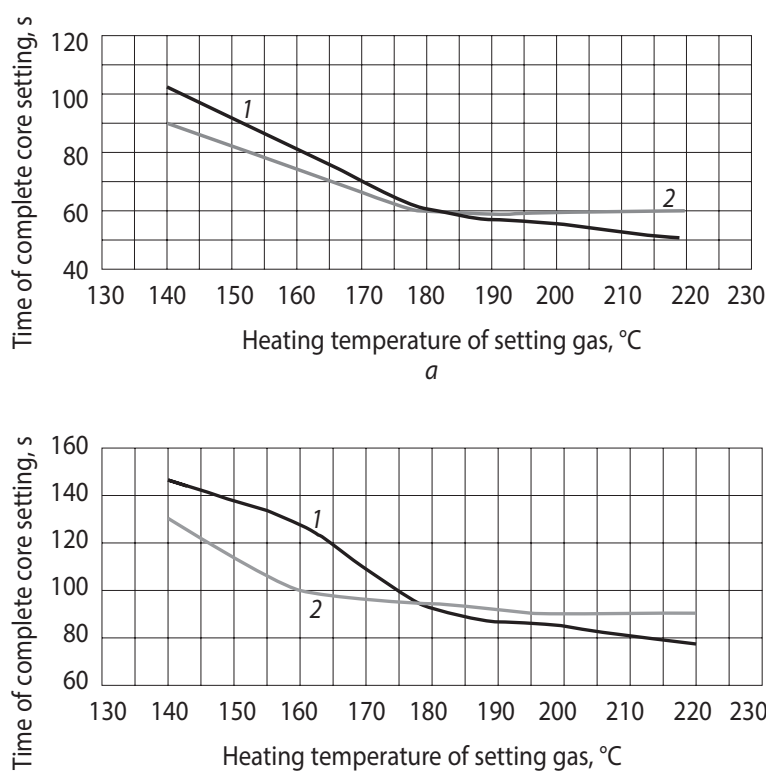

c

cores. Friability of cores surface was controlled additionally. The measurement results were compared with the chosen basic variant [15].

At the heating temperature of supplied air less than $180{ }^{\circ} \mathrm{C}$, all pilot cores have setting time exceeding setting time of the basic variant (fig. 1), while during heating above $200{ }^{\circ} \mathrm{C}$ increased friability was revealed. It allowed to choose the temperature range of setting gas as 180 $200{ }^{\circ} \mathrm{C}$ as the optimal one.
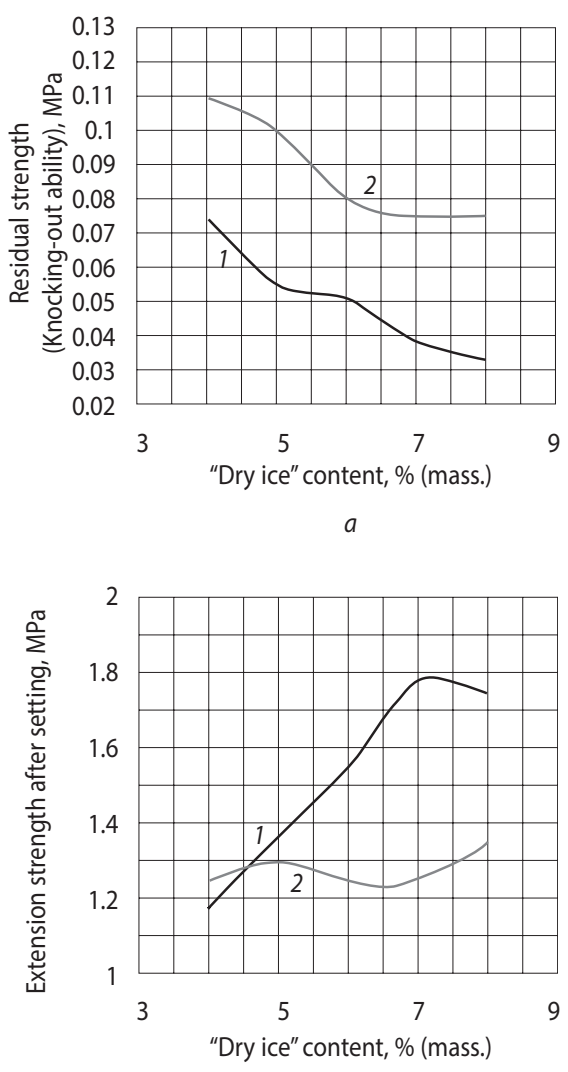

c

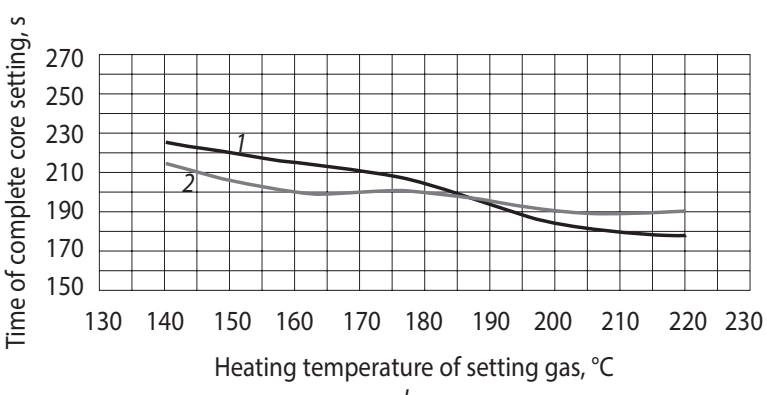

$b$

Fig. 1. Experimental determination of the optimal heating temperature range for setting gas:

$a-0.5 \mathrm{~kg}$ mass core; $b-1.2 \mathrm{~kg}$ mass core; $c-5.0 \mathrm{~kg}$ mass core; 1 - Pilot core; 2 - Basic variant

Then optimal values of particles size and "dry ice" content in the mix were determined experimentally. Evaluation was conducted on strength, friability, gas penetration and knocking-out ability of pilot samples obtained using setting gas heated up to $180-200{ }^{\circ} \mathrm{C}$ was conducted via varying of content in the mix and size of solid carbon dioxide particles.

The mix strength was measured according to the GOST 23409.7 on the "figure-eight" samples after their

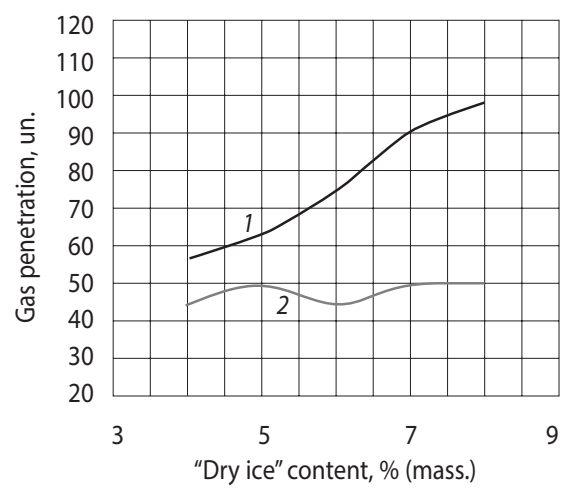

b

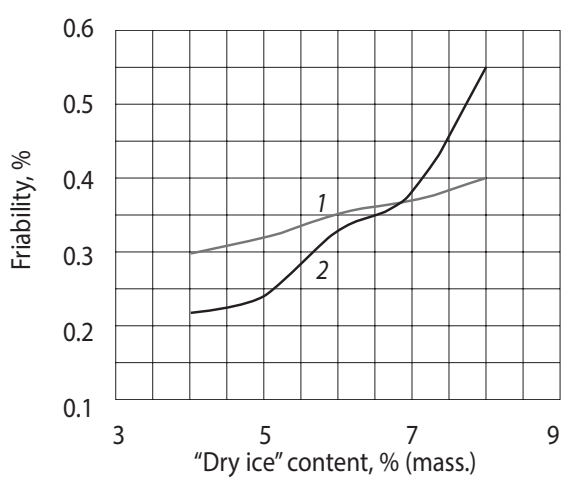

d
Fig. 2. Properties of pilot samples in comparison with the basic variant: $a-$ Knockingout ability; $b-$ Extension strength after setting; $c-$ Gas penetration; $d-$ Friablity;

1 - Pilot core; 2- Basic variant 
complete setting, while friability was measured in accordance with GOST 23409.9 on the cylinder samples manufactured meeting the requirements of the GOS 23409.6. Gas penetration was determined by the technique of the GOST 23409.6 using the sensor of 04315 sort.

Friability of cores was evaluated based on residual strength of samples manufactured via determined strengthening procedure, after their secondary heating up to $900{ }^{\circ} \mathrm{C}$ and consequent cooling; they imitate the effect of metallic melt on core (mould). The measurement results were compared with the basic variant [15].

The conducted analysis of experimental results displayed that stable high level of knocking-out ability (minimal residual strength), mechanical properties and gas penetration, as well as less friability of the pilot samples in comparison with the basic variant are achieved when the mix contains solid carbon dioxide as much as 5-7\% (mass.) in the form of particles with size in the range $0.5-2.0 \mathrm{~mm}$ (fig. 2).

It was established that knocking-out ability of samples manufactured via the suggested variant is better than that for the basic variant approximately by 2 times. In the same way extension strength after setting and gas penetration of obtained samples are higher by $30 \%$ and 2.0-2.5 times respectively in comparison with the basic variant, while friability is lower than this parameter for the basic variant.

\section{Operating testing in the industrial conditions}

The pilot batches of castings "Cover" (made of SCh20 iron according to the GOST 1412, with mass $15 \mathrm{~kg}$ and having the core with mass $2.8 \mathrm{~kg}$ ) and "Balancing lever" (made of 35L steel according to the GOST 977, with mass $22 \mathrm{~kg}$ and having the core with mass $4.5 \mathrm{~kg}$ ) were manufactured at the production site of Nizhniy Novgorod scientific and research institute of machine-building materials "Prometey". Each batch includes 10 castings for developed and basic technological routes.

Waterglass mixture on the base of quartzite sand of $1 \mathrm{~K}_{1} \mathrm{O}_{1} 03$ grade (according to the GOST 2138-91) contained $5.0 \%$ (mass.) of sodium waterglass with 2.8 module and $1.25 \mathrm{~g} / \mathrm{cm}^{3}$ density. This mixture was prepared using paddle blade-type mixer, filling of the core box was conducted in manual technique. Atmospheric air heated up to $180{ }^{\circ} \mathrm{C}$ was used as setting gas. Vacuum treatment of core boxes was conducted with $0.05 \mathrm{MPa}$ exhausting. Presence of defects caused by insufficient quality level of moulding cores (such as geometrical deviations, surface contaminations, non-metallic inclusions, gas porosity) was controlled in the castings.

One of the "Cover" castings manufactured via the basic variant was rejected after testing owing to core destruction during metal pouring; two "Balancing lever" castings were also rejected due to gas porosity caused by insufficient gas penetration ability of the core. At the same time all castings manufactured via the developed technology were valid.

\section{Conclusions}

Practical testing has completely proved efficiency of the developed and suggested technological variant of castings manufacture in the conditions of operating production facilities.

The research was conducted at the expenses of subvention within the framework of the state support of Kazan Federal University among the leading global science and education centers.

\section{REFERENCES}

1. Illarionov I. E., Petrova N. V., Makarov S. G. Waterglass mixtures for manufacture of steel and iron castings. Innovations in education process. Proceedings of the scientific and practical conference. 2017. pp. 78-82.

2. Firstov A. P. Porous structure of waterglass mixture. Evraziyskoe Nauchnoe Obyedinenie. 2019. No. 11-2 (57). pp. 148-151.

3. Rymar T. E. Influence of mineral additives on the formation of a porous structure in liquid-glass granular heat-insulating materials. Voprosy Khimii i Khimicheskoi Tekhnologii. 2019. Iss. 2. pp. 112-120.

4. Aji D. P. B., Johari G. P. Effect of incongruent crystallization on glass-liquid transition features of a bulk metal glass. Thermochimica Acta. 2015. Vol. 615. No. 10. pp. 72-80.

5. Chernyshev E. A., Evlampiev A. A., Guseva O. B. Monitoring of ecological compatibility in fabrication of moulds and cores. Ekologiya i promyshlennost Rossii. 2013. No. 11. pp. 58-61.

6. Thu A. H., Zakharov A. I. Preparation of Inorganic Binder for Cold-Hardening Mixtures. Refractories and industrial ceramics. 2018. No. 9. Vol. 59. Iss. 3. pp. 313-317.

7. Kidalov N. A. Adamova A. S., Khotko A. A., Popov D. I. The effect of setting method for waterglass mixtures on their mechanical properties. Modern technologies in machine-building and foundry production: Proceedings of the III International scientific and practical conference. 2017. pp. 189-194.

8. Krutilin A. N., Guminskiy Yu. Yu., Rusevich O. A., Kulbitskaya L. V. Efficiency rise of use of waterglass mixtures. Part 4. Combined strengthening. Lityo i metallurgiya. 2018. No. 4 (93). pp. 38-44.

9. Firstov A. P. Necessary explanation to the question of time required for blowing of waterglass mixture. Teoriya $i$ tekhnologiya metallurgicheskogo proizvodstva. 2019. No. 4 (31). pp. 35-38.

10. Ivanova L. A., Kuznetsov S. A. Study of deformability of moulds for different binders. The future of Russian machine-building: Proceedings of the $9^{\text {th }}$ All-Russian conference of young scientists and specialists. 2016. pp. 137-140.

11. Voskovets V. G., Litvinenko O. N. Vacuum drying of waterglass mixtures. Vestnik Kharkovskogo politekhnicheskogo instituta. 1981. Iss. 8. pp. 45-47.

12. Ivanov V. G., Kuzovov A. F., Malyi A. V., Karginov V. P., Kolos A. A., Doroshenko A. V. Universal additive for improvement of knocking-out ability of waterglass mixture. Liteynoe proizvodstvo. 2015. No. 8. pp. $10-12$.

13. Kidalov N. A., Melikhov A. V. Choice of organic additives in compositions of waterglass mixtures. Theory and practice of casting processes: Collection of works. 2012. pp. 125-128.

14. Illarionov I. E., Petrova N. V., Makarov S. G., Mulyukhin N. V. Study of waterglass mixtures for manufacture of steel and iron castings. Modern technologies in machine-building and foundry production: Proceedings of the I International scientific and practical conference. 2015. pp. 170-175.

15. Itkis Z. Ya. et al. The method of manufacture of moulding cores and moulds made of waterglass mixtures. RF Patent No. 2094164: MPK B22 C9/10, B22 C9/12. Patent owner: Chelyabinsk State Technical University. Published 27.10.1997.

16. Leushin I. O., Koshelev O. S., Leushina L. I., Nishchenkov A. V. Use of dry ice in fabrication of moulding cores and moulds of waterglass mixtures. Liteynoe proizvodstvo. 2020. No. 8. pp. 8-12. 